\title{
Synthetic Seed Production as a Tool for the Conservation and Domestication of Celastrus paniculatus: A Rare Medicinal Plant
}

\author{
D. L. C. K. Fonseka ${ }^{1^{*}}$, W. W. U. I. Wickramaarachchi ${ }^{1}$ and R. P. S. Madushani ${ }^{1}$ \\ ${ }^{1}$ Department of Crop Science, Faculty of Agriculture, University of Ruhuna, Matara, Sri Lanka.
}

Authors' contributions

This work was carried out in collaboration among all authors. All authors read and approved the final manuscript.

Article Information

DOI: 10.9734/ARRB/2019/v32i430091

Editor(s):

(1) Dr. Eshrat Halim, University of Toronto, Canadian Diabetes Association, Canada and Department of Laboratory Medicine, All India Institute of Medical Sciences, New Delhi, India. (2) Prof. George Perry, Dean and Professor of Biology, University of Texas at San Antonio, USA. Reviewers:

(1) Yash Gupte, Ramnarain Ruia College, India. (2) R. Mahalakshmi, India. (3) Valdir Florencio da Veiga Junior, Military Institute of Engineering, Brazil. Complete Peer review History: http://www.sdiarticle3.com/review-history/44552

Original Research Article

Received 25 October 2018

Accepted 07 January 2019

Published 01 August 2019

\begin{abstract}
The black-oil tree (Celastrus paniculatus Willd) is a highly valued medicinal plant species belong to the Celastraceae family, known as Jyothishmathi in Ayurveda and Duhundu in Sri Lanka and grows as a perennial vine. It is an endangered medicinal plant species recorded in the red list of endangered fauna and flora of Sri Lanka in 1999. The seed oil of Celastrus paniculatus contains sesquiterpene alkaloids namely; celapagine, celapanigine, celapanine and celastrol, used in traditional system of medicine for various disorders and because of its high pharmaceutical value, plants are over exploited in natural habitats. Owing to poor seed germination and lack of successful vegetative propagation methods, domestication and commercial planting of this important medicinal plant species to meet the demand seems impossible. Therefore, it is of high importance to develop a reliable and efficient in vitro propagation to produce black oil plants for commercial use. In this study, it was attempted to produce synthetic seeds of Celestrus paniculatus via in vitro multiple shoot proliferation. Nodal segment explants were collected from freshly emerged age of sprouts, surface sterilized and cultured in Murashige and Skoog medium supplemented with different 6-
\end{abstract}


benzylaminopurine (BAP) and Thidiazuron (TDZ) concentrations for shoot induction. The highest soot proliferation rate; 25 shoot tips/explant were observed with $0.1 \mathrm{mg} / \mathrm{L} \mathrm{TDZ}$. Induced shoot tips were used for synthetic seed production after encapsulating with BAP and a-naphthalene acetic (NAA) enriched sodium alginate. Shoot tip encapsulated beads produced with $4 \%$ sodium alginate were firm, clear, round and uniform in size and easy to handle. The influence of growth regulators (BAP and NAA) and storage period on the germination of encapsulated shoot tips was studied to evaluate the success of encapsulated shoot tips as a propagule. The beads germinated with $2 \mathrm{mg} / \mathrm{L}$ BAP and $0.2 \mathrm{mg} / \mathrm{L}$ NAA provided $80 \%$ in vitro germination percentage. Shoot tips of synthetic seeds remained green and healthy after storage at $5^{\circ} \mathrm{C}$ for a period of 8 weeks. Current findings suggest that encapsulated micro shoots (synthetic seeds) could be produced successfully, as the first step in domestication and conservation of Celastrus paniculatus. Further studies required on rooting of micro shoots, acclimatization and transferring of plantlets produced from synthetic seeds to in vivo conditions for domestication and conservation purposes.

Keywords: Celastrus paniculatus; conservation; germination; growth regulators; medicinal plants; synthetic seeds.

\section{INTRODUCTION}

The black-oil tree (Celastrus paniculatus Willd), locally known as Duhundu, Jyotishmati in India belongs to the Celastraceae family, is an endangered medicinal plant species recorded in the red list of endangered fauna and flora of Sri Lanka in 1999, as well as in Indian subcontinent $[1,2]$. This plant is widely used in Ayurveda to cure many diseases such as leprosy, leucoderma, skin diseases, paralysis, depression, arthritis, asthma and fever [3]. The seed oil of Celastrus paniculatus Willd contain sesquiterpene alkaloids namely; celapagine, celapanigine, celapanine and celastrol, used in traditional system of medicine for various disorders. The plants exhibit varying degrees of therapeutic values, some of which are its use in the treatment of cognitive dysfunction, epilepsy, insomnia, rheumatism, gout, dyspepsia [4].

Because of high pharmaceutical value and lack of domesticated or commercial plantings, plants in natural habitats are over exploited. Owing to poor seed germination and lack of successful vegetative propagation methods, mass propagation of this important medicinal plant species seems impossible. Therefore, it is of high importance to develop a reliable and efficient method for conservation and commercial cultivation of black oil tree [5].

Conventionally, C. paniculatus is propagated mainly through the seeds. However, the viability and germination of the seeds $(11.5 \%)$ are poor [6]. Thus, alternative approaches such as in vitro techniques are highly desirable for large- scale propagation of this medicinally important plant. Polymerization of sodium alginate in calcium chloride $\left(\mathrm{CaCl}_{2}\right)$ resulted in the formation of hydrogel capsules with a somatic embryo (SE) or with propagules inside, called artificial seeds (ASs) or synthetic seeds. Artificial seed technology is an implementation of modern plant biotechnology, which offers tremendous potential in micropropagation as well as germplasm conservation of rare, endangered plants along with its easy handling and transportation [7]. In this backdrop, the present study was conducted to explore the possibility of multiple shoot proliferation and synthetic seed production of Celestrus paniculatus with the aim of initiating commercial cultivation through domestication.

\section{MATERIALS AND METHODS}

\subsection{Plant Material and Surface Sterilization}

Mother plants of Celestrus paniculatus are maintained at the Department of Crop Science, Faculty of Agriculture, University of Ruhuna, Sri Lanka under protected house conditions and nodal segment explants $(2-4 \mathrm{~mm})$ were collected from freshly emerged sprouts. Explants were washed thoroughly in running tap water and washed with detergent 'Teepol' for $5 \mathrm{~min}$ and surface sterilized with $10 \%$ Clorox for 10 minutes. The disinfected explants are washed (3-4 washes) with sterile double distilled water to remove traces of sterilant. Nodal segments (3-5 mm) were cultured in Murashige and Skoog [8] medium supplemented with different BAP and TDZ concentrations for shoot induction. 


\subsection{Media Preparation and Culture Condition}

All the experiments were carried out on Murashige and Skoog [8] basal medium containing $3.0 \%(\mathrm{w} / \mathrm{v})$ sucrose as a carbon source and, $0.8 \%(\mathrm{w} / \mathrm{v})$ agar for gelling was adjusted to $5.8 \mathrm{pH}$, and sterilized in an autoclave under $15 \mathrm{psi}$ at $121^{\circ} \mathrm{C}$. All the equipment and reagents were autoclaved at $121^{\circ} \mathrm{C}$ and $15 \mathrm{psi}$ for 15 minutes. The medium was supplemented with various concentrations and combinations of auxin [a-naphthalene acetic (NAA) $(0.1$ and 0.2 $\mathrm{mg} / \mathrm{L})$ ], cytokinin [6-benzylaminopurine (BAP) $(0.5,1.0,1.5$ and $2.0 \mathrm{mg} / \mathrm{L})$ and thidiazuron (TDZ) $(0.1$ and $0.2 \mathrm{mg} / \mathrm{L})$ ] for shoot proliferation of nodal segments. All cultures were sub cultured to their respective fresh medium at every 3-week intervals. For the encapsulation of nodal segments, the encapsulation medium (EM) was prepared by slight modification of MS basal medium. The EM is devoid of calcium salt and agar but fortified with $3.0 \%$ sucrose and sodium alginate. For optimizing encapsulation sodium alginate solution was prepared in liquid Murashige and Skoog's (MS) medium at the different weight is to volume concentrations (2$5 \%$ ). The $\mathrm{pH}$ of the medium was adjusted to 5.6 prior addition of sodium alginate. For polymerization calcium chloride $\left(\mathrm{CaCl}_{2}\right)$ solutions of $100 \mathrm{mmolL}^{-1}$ strength was prepared in double distilled water. To test the regeneration and germination of artificial seeds combinations of NAA and BAP were used. All cultures were incubated at $25 \pm 2^{\circ} \mathrm{C}$ with $16 / 8 \mathrm{~h}$ photoperiod under the white fluorescent light.

\subsection{Shoot Induction and Proliferation}

All the surface sterilized explants $(3-5 \mathrm{~mm}$ ) were cultured MS medium supplemented with two different concentrations $(0.1$ and $0.2 \mathrm{mg} / \mathrm{L})$ of NAA in combination with 6-BAP $(0.5-2.0 \mathrm{mg} / \mathrm{L})$ and TDZ (0.1 and $0.2 \mathrm{mg} / \mathrm{L})$ as shown in Table 1. All the cultures were incubated under $25 \pm 2^{\circ} \mathrm{C}$ with $16 / 8 \mathrm{~h}$ photoperiod under the white fluorescent light. The percentage of shoot induction, number of shoots per explant were obtained after 12 days and shoot proliferation rate was recorded at weekly intervals for ten weeks.

\subsection{Synthetic Seed Preparation}

In vitro produced nodal segments $[(4 \pm 1) \mathrm{mm}$ long),] were drenched for 10 minutes with autoclaved sterilized $2 \%, 3 \%, 4 \%$ and $5 \%(\mathrm{w} / \mathrm{v})$ Sodium alginate (NA) gelling matrix dissolved in calcium-free $1 / 2 \mathrm{MS}$ liquid medium. For the development of artificial seeds, the aliquots (0.2 $\mathrm{mL}$ approx.) of NA solution, each containing single micro shoot (nodal segment), were taken aseptically by a Pasteur pipette ( $5 \mathrm{~mm}$ diameter) and softly dropped one by one in $100 \mathrm{mmolL}^{-1}$ autoclaved $\mathrm{CaCl}_{2} \cdot 2 \mathrm{H}_{2} \mathrm{O}$ (CC) liquid. For optimum polymerization, the droplets were kept for 30 minutes in CC with constant agitation to allow absolute polymerization. Polymerization can be measured apparently as the artificial seeds become translucent instantly next to the formation and then displays an opaque nature as the polymerization proceeds [9]. The CC solution was then decanted and the artificial seeds were double washed with sterile water. Immediately after, the beads were surface dried by blotting on filter paper. The bead formation was compared after a complexion time of $30 \mathrm{~min}$ for all the treatments. The artificial seeds were kept under appropriate incubating conditions.

\subsection{Culture Conditions and Synthetic Seed Germination}

Encapsulated and non-encapsulated nodal segments were kept in petri dishes sealed with paraffin film and kept in three different temperature regimes $\left((5 \pm 1)^{\circ} \mathrm{C},(15 \pm 1)^{\circ} \mathrm{C}\right.$, and $\left.(25 \pm 1)^{\circ} \mathrm{C}\right)$ without illumination. For storing at $(5$ $\pm 1)^{\circ} \mathrm{C}$, tubes were kept in the refrigerator, for $(15$ $\pm 1)^{\circ} \mathrm{C}$ in an incubator whereas for $(25 \pm 1)^{\circ} \mathrm{C}$ the tubes were maintained in culture room.

These were tested for germination competence on regeneration media in culture tube, after every two weeks (up to 8 weeks) on $1 / 2$ MS medium having $3 \%$ sucrose $(\mathrm{w} / \mathrm{v})$ supplemented with two different concentrations $(0.1$ and $0.2 \mathrm{mg} / \mathrm{L})$ of NAA in combination with 6-BAP $(1.0-5.0 \mathrm{mg} / \mathrm{L})$ and were maintained for 6 weeks at $24 \pm 2^{\circ} \mathrm{C}$ and $55-65 \%$ relative humidity with $16 / 8 \mathrm{~h}$ light and dark period, light was provided by cool fluorescent white lamps (Table 2).

\subsection{Statistical Assessment}

Experimentations were replicated twice comprising 5 samples for each replication following completely randomized design. Data were statistically assessed through One-way analysis of variance (ANOVA). Treatment data (Means \pm SE) were evaluated based on Duncan's multiple range test (DMRT) (Duncan, 1955) $(P \leq 0.05)$ through SAS 9.4 software. 
Table 1. Effect of plant growth regulators on shoot induction of explants (after 12 days) and average no of shoots (after 9 weeks) of culture

\begin{tabular}{|c|c|c|c|c|}
\hline \multicolumn{3}{|c|}{ Growth regulator concentration (mg/L) } & \multirow[t]{2}{*}{ Shoot induction (\%) } & \multirow{2}{*}{$\begin{array}{l}\text { Average number of } \\
\text { shoots/explant }\end{array}$} \\
\hline NAA & BAP & TDZ & & \\
\hline 0.1 & 0.5 & - & 70.4 & $16.0 \pm 0.02^{9}$ \\
\hline 0.1 & 1.0 & - & 76.2 & $17.2 \pm 0.01^{\dagger}$ \\
\hline 0.1 & 1.5 & - & 80.8 & $18.0 \pm 0.04^{\mathrm{e}}$ \\
\hline 0.1 & 2.0 & - & 97.8 & $25.2 \pm 0.02^{\mathrm{a}}$ \\
\hline 0.2 & 0.5 & - & 66.8 & $13.2 \pm 0.04^{\mathrm{h}}$ \\
\hline 0.2 & 1.0 & - & 82.4 & $20.6 \pm 0.07^{\mathrm{d}}$ \\
\hline 0.2 & 1.5 & - & 85.2 & $22.8 \pm 0.02^{c}$ \\
\hline 0.2 & 2.0 & - & 85.2 & $20.8 \pm 0.06^{d}$ \\
\hline 0.0 & 0.0 & 0.1 & 88.2 & $24.4 \pm 0.06^{\mathrm{b}}$ \\
\hline 0.0 & 0.0 & 0.2 & 92.4 & $25.0 \pm 0.01^{\mathrm{a}}$ \\
\hline
\end{tabular}

Means in each column followed by the same superscript letters are not significantly different according to DMRT at $P<0.05$

Table 2. Germination percentage and number of shoots produced from synthetic seeds produced from Celastrus paniculatus willd

\begin{tabular}{llll}
\hline NAA (mg/L) & BAP $(\mathbf{m g} / \mathbf{L})$ & Germination percentage & Shoot no. \\
\hline 0.1 & 0.5 & $85.57 \pm 0.59^{\mathrm{de}}$ & $1.26 \pm 0.01^{\mathrm{e}}$ \\
0.1 & 1.0 & $87.83 \pm 1.00^{\mathrm{cd}}$ & $1.86 \pm 0.05^{\mathrm{c}}$ \\
0.1 & 1.5 & $89.46 \pm 0.69^{\mathrm{bc}}$ & $1.48 \pm 0.02^{\mathrm{d}}$ \\
0.1 & 2.0 & $94.43 \pm 0.74^{\mathrm{a}}$ & $2.38 \pm 0.10^{\mathrm{a}}$ \\
0.1 & 2.5 & $85.00 \pm 1.00^{\mathrm{e}}$ & $1.13 \pm 0.06^{\mathrm{ef}}$ \\
0.1 & 3.0 & $71.18 \pm 1.04^{\mathrm{h}}$ & $0.99 \pm 0.01^{\dagger}$ \\
0.2 & 0.5 & $74.13 \pm 0.42^{\mathrm{g}}$ & $1.20 \pm 0.05^{\mathrm{e}}$ \\
0.2 & 1.0 & $80.53 \pm 0.57^{\dagger}$ & $1.25 \pm 0.02^{\mathrm{e}}$ \\
0.2 & 1.5 & $68.57 \pm 0.39^{\mathrm{i}}$ & $1.00 \pm 0.02^{\dagger}$ \\
0.2 & 2.0 & $62.08 \pm 1.01^{\mathrm{j}}$ & $0.97 \pm 0.01^{\mathrm{j}}$ \\
0.2 & 2.5 & $89.27 \pm 1.10^{\mathrm{c}}$ & $1.29 \pm 0.01^{\mathrm{e}}$ \\
0.2 & 3.0 & $91.87 \pm 0.90^{\mathrm{b}}$ & $2.20 \pm 0.1^{\mathrm{b}}$ \\
\hline Means in each column followed by the same superscript letters are not significantly different according to DMRT
\end{tabular}

\section{RESULTS AND DISCUSSION}

\subsection{In vitro Shoot Induction Proliferation}

A simple and effective protocol was developed for the in vitro micro propagation of Celestrus paniculatus. Immature nodal segments were cultured on MS medium containing different concentrations of BAP and NAA to evaluate their effects on shoot initiation. Explants showed varying success in shoot initiation depending on the growth regulators added. The response of explants cultured in MS media supplemented with BAP, NAA and TDZ are shown in Table 1.

Bud break was observed for the explants cultured on MS medium containing cytokinins (BAP or TDZ) after 12 days. The increased level of BAP resulted in significantly higher shoot initiation and the number of shoots at the initiation stage, with a constant level of NAA. Although bud break was dependent on BAP supply, the synergistic combination of BAP and NAA induced the optimum frequency of shoot formation as well as shoot number. The highest rate of shoot induction (97.8\%) which was significantly different from all other hormonal combinations used at 5\% significant level and highest number of shoots per explant (25.2) were obtained in MS medium supplemented with 2.0 $\mathrm{mg} / \mathrm{l} \mathrm{BAP}+0.1 \mathrm{mg} / \mathrm{L}$ NAA after nine weeks of nodal culture (Table 1 ). Therefore $9^{\text {th }}$ week is the best period to get an optimum number of shoots from nodal segments. Furthermore, [10] reported that the cotyledonary node explants of Yeheb (Cordeauxia edulis) cultured on MS medium supplemented with $2.0 \mathrm{mg} / \mathrm{L}$ BAP resulted in the highest rate of shoot initiation (89\%) and the highest number of shoots per culture after nine 
weeks. Considering about the effect of TDZ, the highest soot proliferation rate; 25.0 shoot tips/ explant was observed with $0.2 \mathrm{mg} / \mathrm{L}$ TDZ which was not significantly different with the hormonal combination $2.0 \mathrm{mg} / \mathrm{L}$ BAP + $1.0 \mathrm{mg} / \mathrm{L} \mathrm{NAA}$ after nine weeks of nodal culture at $5 \%$ significant level. Nodal explants of Rauvolfia tetraphylla cultured on MS $+5 \mu \mathrm{M}$ TDZ has given optimal $(90 \%)$ regeneration response for maximum $(9.2 \pm$ 1.20) shoot production [11]. Repeated transfer of the cultures was suggested as an efficient technique for rejuvenation and reinvigoration of in vitro cultures (Sanchez et al. 1997), which was further supported by subsequent reports on different plants (Phulwaria et al. 2012b). The importance of plant growth regulators on shoot propagation has been highlighted in various studies. Consistent with this result, Daneshvar et al. (2013) reported that $2.5 \mathrm{mg} / \mathrm{L}$ BAP +0.15 $\mathrm{mg} / \mathrm{L}$ NAA in MS medium produced the highest number of Aloe vera plantlets (up to 28.47 plantlets per explant).

\subsection{Effect of Alginate and Calcium Chloride Concentration on Bead Formation}

Formation of beads with appropriate texture is the key for producing effective synthetic seeds. The stability and hardness are the main two factors affecting the effectiveness of these seeds because very hard beads limit the germination ability while fragile beads limit the handling. NA was chosen for encapsulation because of its minimal toxicity to micro propagules and its rapid gelatinization. The hardiness and firmness of the beads depending on the ion exchange of $\mathrm{Na}^{+}$ and $\mathrm{Ca}^{2+}$ during complexing. Thus, to obtain effective synthetic seeds, concentrations of sodium alginate and calcium chloride and the complexing time needs to be standardized (Rai et al., 2009). The present investigation shows that the polymerizing ability of synthetic seeds varied markedly at different concentrations (2$5 \%$ ) of NA when used to encapsulate the nodal segments. Out of the four different concentrations of NA $(2-5 \%)$, evaluated to develop an encapsulation matrix most appropriate for short-term storage and maximum regeneration.

Lower concentrations resulted in weak structures with no definite shape and disintegrated while handling. Very firm, clear, isodiametric beads of viable, uniform size and shape, were obtained at and above the concentration of 3\% NA upon complexation with $100 \mathrm{mmolL}^{-1} \mathrm{CC}$. It was reported by several researchers that $3 \%$ sodium alginate with $100 \mathrm{mmolL}^{-1} \mathrm{CC}$ was the most ideal combination for synthetic seed production [12]. The beads produced with 4\% NA concentration were firm, clear, round and uniform in size and easy to handle. (Fig. 2C). The results obtained are in agreement with earlier reports in other species $[9,7]$.

\subsection{Regeneration and Germination of Synthetic Seeds}

Synthetic seeds developed using 2, 3, 4, and 5\% NA were tested for their regenerating ability on the regeneration medium as mentioned above. Maximum regeneration was recorded in synthetic seeds developed using 4\% NA, while the regeneration was significantly less in seeds encapsulated with $5 \%$ NA solutions respectively. Similar observations have also been reported by [13]. In our observations, levels on NA lower or higher than $4 \%$ resulted in either too pliable or too firm artificial seeds or subsequently reduced conversion frequencies. The combination of BAP $(3.0 \mathrm{mg} / \mathrm{L})$ and NAA $(0.1 \mathrm{mg} / \mathrm{L}$ and $0.2 \mathrm{mg} / \mathrm{L})$ produced maximum regeneration percentage and a maximum number of shoots (Table 2). However, only shoots immerged and rooting was not observed.

BAP has been documented as one of the most potent cytokinins among others [14], effectively induced organogenesis in several species like Euphorbia cotinifolia [15]. Combination of BAP with different auxins evoked a different response from the tissues, NAA assisted in enhancing adventitious shoots. The difference in response could be attributed to different levels of NAA has been frequently reported to augment adventitious shoot generation along with cytokinins.

\subsection{Effect of Encapsulation on Storage Time}

One of the most important objectives of synthetic seed formation is to increase the storability of the propagules. Therefore, the regeneration ability of the somatic tissues of Celestrus paniculatus stored in encapsulated and non-encapsulated forms at different storage temperatures and storage periods were tested. It was evident from the Fig. 4, that the conversion of artificial seeds after each every two weeks (up to 8 weeks) of storage duration at temperatures $(5 \pm 1)^{\circ} \mathrm{C},(15 \pm 1)^{\circ} \mathrm{C}$ and $(25 \pm 1)^{\circ} \mathrm{C}$ varied markedly relying on the storage environment. 
Encapsulation was found very effective in maintaining the regeneration potential of the tissue. The regeneration potential remained unaffected up to 4 weeks of storage in $5 \pm 1^{\circ} \mathrm{C}$ with $86 \%$ of germination frequency, beyond which a decrease in conversion rate was, recorded (Fig. 4). However, even after 8 weeks of cold storage at $5 \pm 1^{\circ} \mathrm{C}, 27.6 \%$ of synthetic seeds showed regeneration while nonencapsulation nodal segments could not produce any shoots. Similar observations were obtained for the artificial seeds of Erythrina variegate which could be stored up to 8 weeks without lowering the germination ability [9]. There are reports supporting the higher conversion efficiency of synthetic seeds when stored at $5 \pm$ $1^{\circ} \mathrm{C}$. Ikhlaq et al. [16] reported a promising degree of interaction between cold storage at $5 \pm$ $1^{\circ} \mathrm{C}$ and storage up to 45 days for regrowth percentage as well as root and shoot development in olive. After 8 weeks of storage browning of seeds were observed and did not observe any germination. It was observed that the longer storage drastically decreases the conversion frequency, regardless of stored temperature, mainly might be due to the continuation of metabolic events in encapsulated micro shoots and accumulation of secondary metabolites in the matrix causing browning there by limiting the storage potential of the artificial seeds. Encapsulation matrix reduces the dehydration of the tissue and limits oxidation of phenolic compounds, thus, reducing cell death and sustaining the regeneration potential of the tissue up to a longer duration than the nonencapsulated tissues. Our results agreed on the findings of Alatar et al. [13].

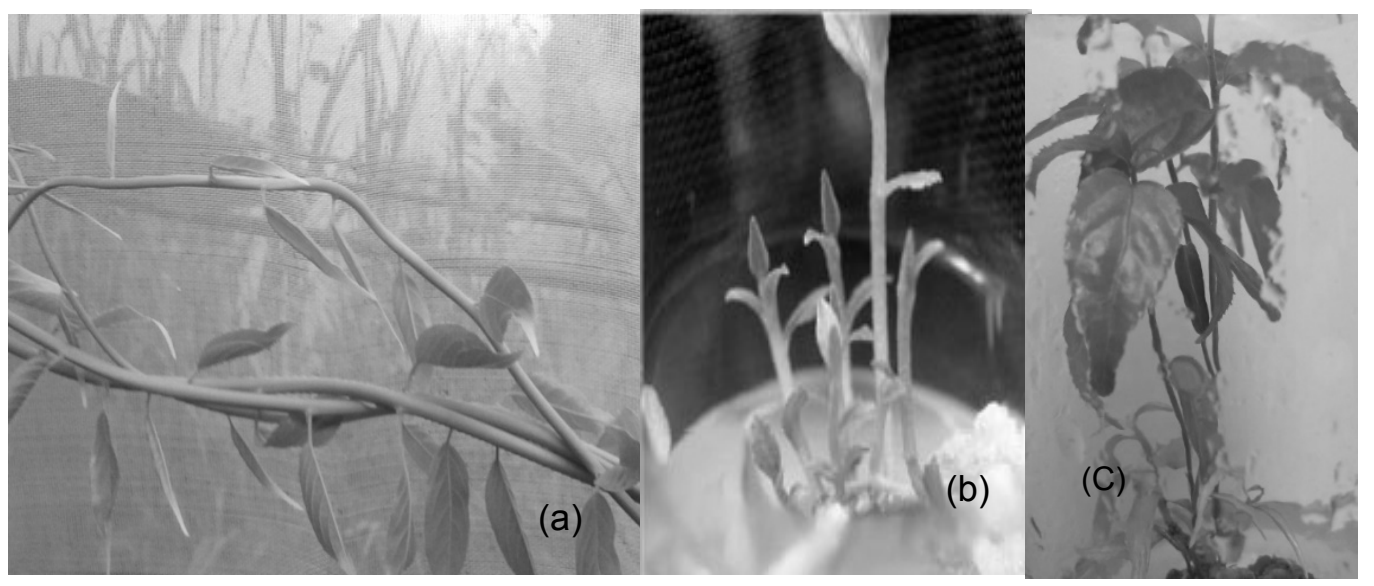

Fig. 1. Stages of multiple shoot induction of C. panicualtus. (a) Mother pant (b) Multiple shoot induction (c) proliferated shoots
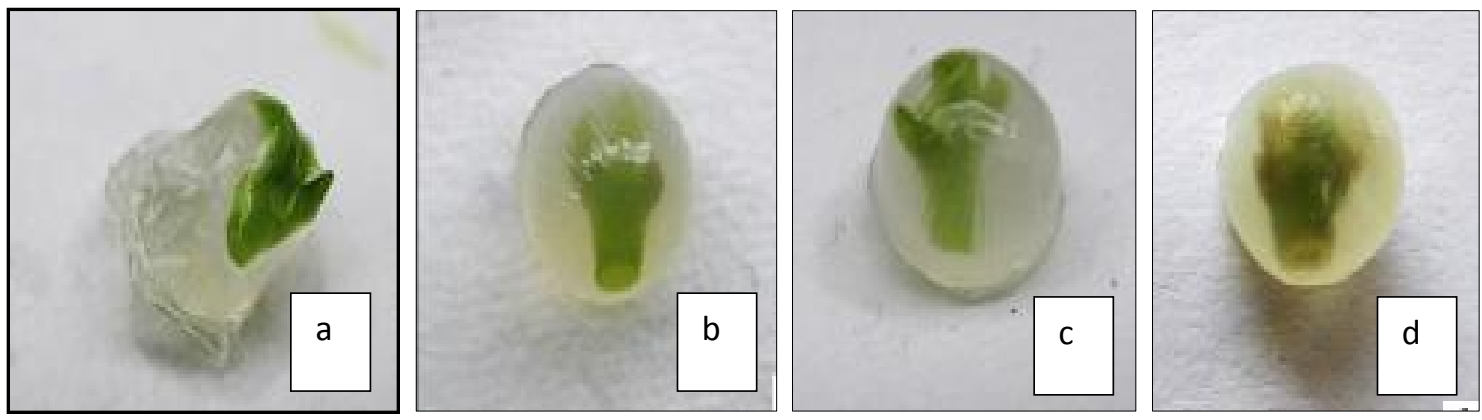

Fig. 2. Influence of $\mathrm{CaCl}_{2}$ and Na-alginate on the shape and consistency of artificial seeds (Encapsulated in vitro-derived nodal segments) of Celastrus paniculatus Wild. a: with $2 \%$ NA; b: $3 \%$ NA; c: $4 \%$ $N A$; $d$ : with $5 \% N A$ 


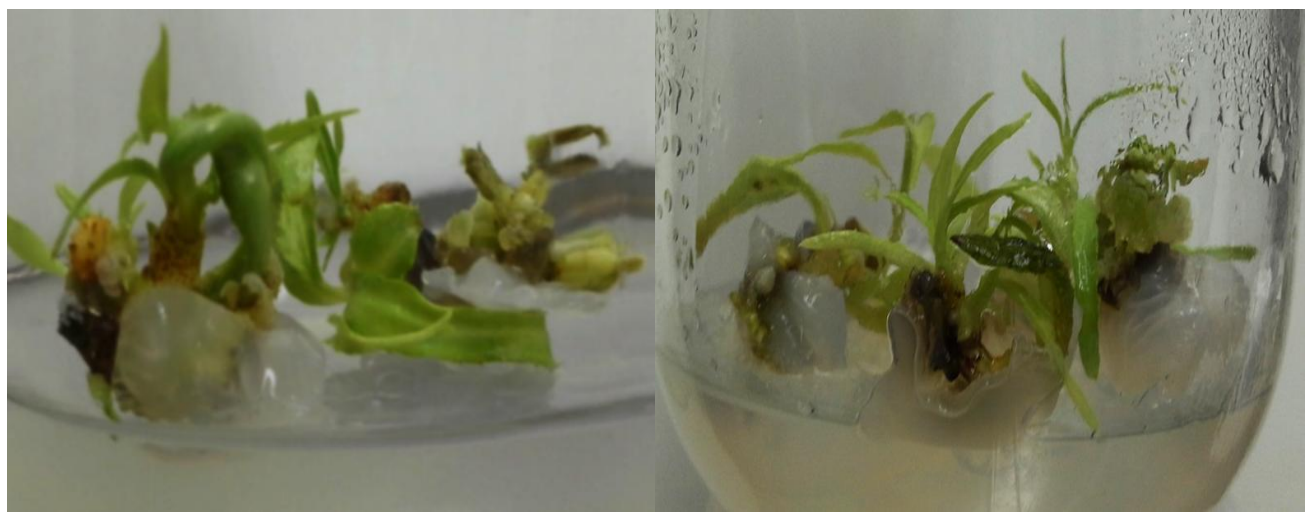

Fig. 3. In vitro germination percentage of Celastrus paniculatus synthetic seeds

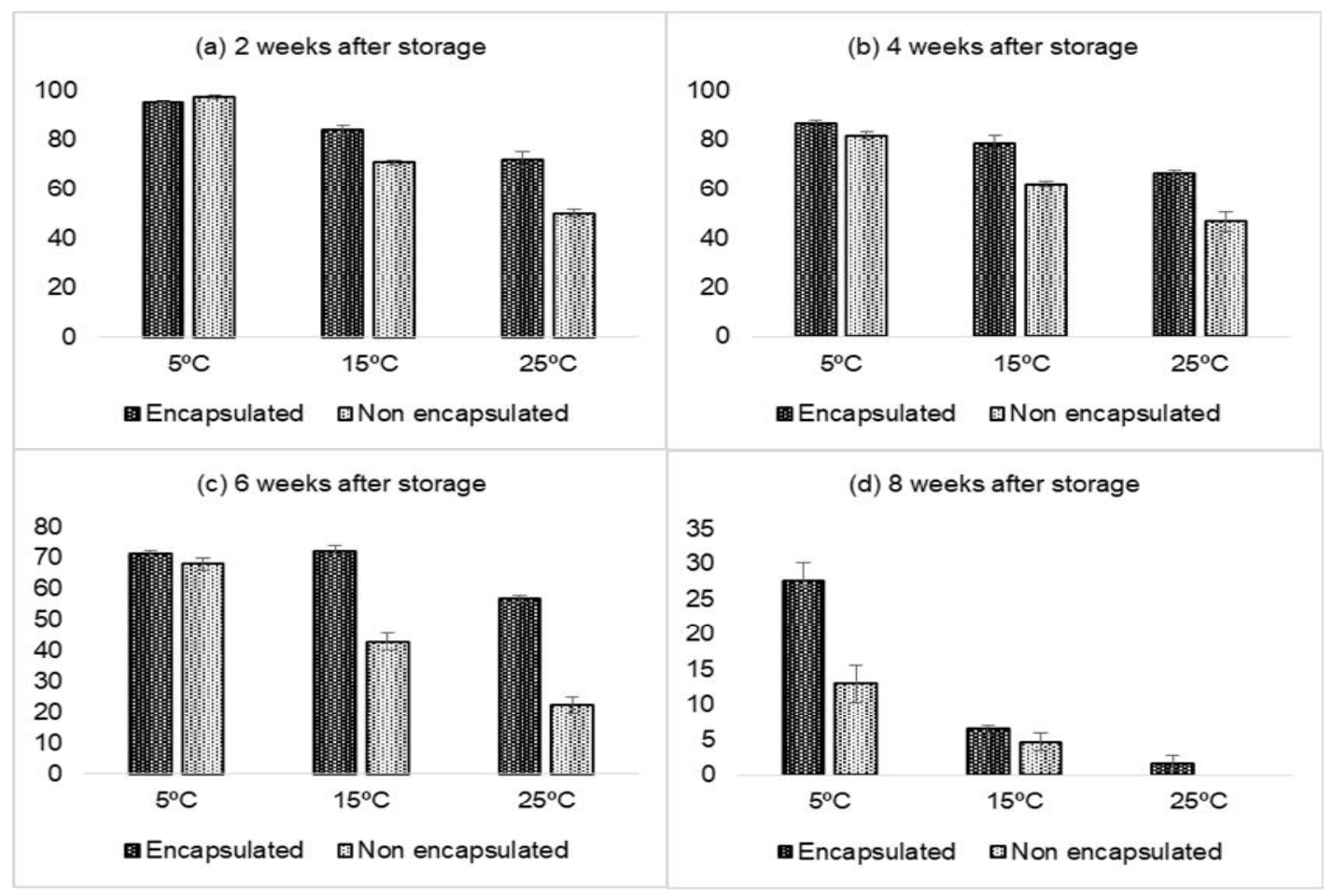

Fig. 4. Conversion responses of encapsulated and non-encapsulated nodal segments of Celastrus paniculatus Willd at two weeks intervals

\section{CONCLUSION}

Current findings suggested that nodal segments cultured on MS medium with $0.1 \mathrm{mg} / \mathrm{L}$ TDZ showed highest multiple shoot induction in Celastrus paniculatus. The firm, round shaped and easy to handle beads produced with $4 \% \mathrm{Na}$ Alginate with $100 \mathrm{mmolL}-1 \mathrm{CC}$. Shoot tips of synthetic seeds remained green and healthy after storage at $5^{\circ} \mathrm{C}$ for a period of 8 weeks. Current findings suggest that encapsulated micro shoots (synthetic seeds) could be produced successfully, as the first step in domestication and conservation of Celastrus paniculatus. Further studies required on rooting of micro shoots and acclimatization of plantlets produced from synthetic seeds to in vivo conditions for domestication and conservation purposes.

\section{COMPETING INTERESTS}

Authors have declared that no competing interests exist. 


\section{REFERENCES}

1. Martin G, Geetha SP, Raja SS, Raghu AV, Balachandran I, Ravindran PN. An efficient micropropagation system for Celastrus paniculatus Willd: A vulnerable medicinal plant. Journal of Forest Research. 2006; 11:461-465.

2. Raju NL, Prasad MNV. Influence of growth hormones on adventitious root formation in semi-hardwood cuttings of Celasturs paniculatus Willd: A contribution for rapid multiplication and conservation manage-ment. Agroforestry Systems. 2010;79: 249252.

3. Sharma PC, Yelne MB, Dennis TJ. Database on medicinal plants used in Ayurveda, Central Council for Research in Ayurveda and Sidda. Janakpori, New Delhi. 2001;2.

4. Nadkarni KM, Nadkarni AK, Nadkarni KM. $7^{\text {th }}$. Popular Bombay Prakashan Pvt. Ltd. Indian Materia Medica. 1976;1: 296.

5. Arya V, Singh RP, Shekhawat SN. A micropropagation protocol for mass multiplication and off-site conservation of Celastrus paniculatus - A vulnerable medicinal plant of India, J. Sust. Forest. 2001;14 (1):107-120.

6. Rekha K, MK Bhan, Kak SN, Pal S. Efficacy of chemical treatments in enhancing germination in Celastrus paniculatus. Indian J Plant Physiol. 1998; 3(1):73-75.

7. Gantait S, Vijayan J, Majee A. Artificial seed production of tylophora indica for interim storing and swapping of germplasm. Horticultural Plant Journal. 2017;3(1):41-46.

Available:http://dx.doi.org/10.1016/j.hpj.20 17.06.004

8. Murashige T, Skoog F. A revised medium for rapid growth and bio assays with tobacco tissue cultures. Physiologia Plantarum. 1962;15(3):473-497.
9. Javed SB, et al. Synthetic seeds production and germination studies, for short-term storage and long distance transport of Erythrina variegata L. A multipurpose tree legume. Industrial Crops \& Products. 2017; 105:41-46.

Available:http://dx.doi.org/10.1016/j.indcro p.2017.04.053

10. Seyoum $\mathrm{Y}$, Mekbib F. In vitro germination and direct shoot induction of Yeheb (Cordeauxia edulis Hemsl.). 2014;3(6): 452-458.

11. Ahmad N, Faisal M. Thidiazuron: From urea derivative to plant growth regulator. Thidiazuron: From Urea Derivative to Plant Growth Regulator. 2018;1-491.

12. Sharma $S$, Shahzad A, Teixeira da Silva JA. Synseed technology- A complete synthesis. Biotechnology Advances. 2013;31(2):186-207.

Available:http://dx.doi.org/10.1016/j.biotech adv.2012.09.007

13. Alatar AA, et al. Two-way germination system of encapsulated clonal propagules of Vitex trifolia L.: An important medicinal plant. Journal of Horticultural Science and Biotechnology. 2017;92(2):175-182.

Available:http://dx.doi.org/10.1080/146203 16.2016.1234949

14. Arab Mohammad, Yadollahi Abbas, Shojaeiyan Abdolali, Shokri Saber, Maleki Ghojah, Shoresh. Effects of nutrient media, different cytokinin types and their concentrations on in vitro multiplication of G×N15 (hybrid of almond×peach) vegetative rootstock. Journal of Genetic Engineering and Biotechnology. 2014;12: 81-87.

DOI: 10.1016/j.jgeb.2014.10.001

15. Perveen S, Javed SB, Anis M, et al. Acta physiol plant. 2013;35:3391.

Available:https://doi.org/10.1007/s11738013-1374-y

16. Ikhlaq M, Hafiz IA, Micheli M, Ahmad T. In vitro storage of synthetic seeds: Effect of different storage conditions and intervals on their conversion ability Afr J Biotechnol. 2010;9(35):5712-5721.

(c) 2019 Fonseka et al.; This is an Open Access article distributed under the terms of the Creative Commons Attribution License (http://creativecommons.org/licenses/by/4.0), which permits unrestricted use, distribution, and reproduction in any medium, provided the original work is properly cited.

Peer-review history:

The peer review history for this paper can be accessed here: http://www.sdiarticle3.com/review-history/44552 